\title{
Chapter 18 \\ New and Promising Targeted Therapies in First and Second-Line Settings
}

\author{
Dylan F. Roden, Jennifer M. Johnson, Petr Szturz, Paolo Bossi, \\ and Athanassios Argiris
}

\section{Introduction}

The increasing efficiency and decreasing cost of next generation DNA sequencing (NGS) has allowed for a better understanding of the complex molecular pathways that contribute to carcinogenesis [1]. Utilizing these improved techniques, cancer genomes can now be systematically studied. Unfortunately, separating the "driver" mutations responsible for carcinogenesis from the "passenger genes" is not straightforward, and the clinical relevance of certain mutations continues to be debated.

Several large scale projects across the globe have accomplished the characterization of cancer genomes. The Cancer Genome Atlas (TCGA) Program is a joint venture between the National Cancer Institute and the National Human Genome Research Institute representing 20 institutions across the US and Canada. Since its inception in 2006 it has molecularly characterized over 20,000 cancer genomes with matched normal samples spanning 33 cancer types. The International Cancer

\footnotetext{
D. F. Roden

Department of Otolaryngology- Head and Neck Surgery, New Jersey Medical School, Rutgers University, Newark, NJ, USA

e-mail: Dylan.Roden@Rutgers.edu

\section{J. M. Johnson · A. Argiris ( $\bowtie)$}

Department of Medical Oncology, Thomas Jefferson University, Philadelphia, PA, USA

e-mail: Jennifer.M.Johnson@ Jefferson.edu; Athanassios.Argiris@ Jefferson.edu

P. Szturz

Department of Oncology, Lausanne University Hospital (CHUV), Lausanne, Switzerland

P. Bossi

Department of Medical Oncology, University of Brescia, Brescia, Italy

e-mail: Paolo.Bossi@Unibs.it
} 
Genome Consortium and the COSMIC database have also helped to establish baseline mutational profiles in many cancer pathologies [2].

A genomic characterization of HNSCCwas published in Nature based on 279 tumor included in TCGA [3]. It showed high genomic instability with a mean copy number alteration of 141 and a relative paucity of gene fusion mutations that are implicated in other solid tumors [3]. A genomic difference in Human Papilloma Virus (HPV) negative and HPV positive tumors was seen, with most HPV negative tumors having loss of p53 (84\%) and deletion of CDKN2A (58\%) whereas HPV positive tumors more commonly had amplification mutations in PIK3CA $(56 \%)$. Consistent with the effects of tobacco exposure, HPV negative tumors harbor a much larger number of chromosomal alterations and amplifications compared to HPV positive tumors [4].

HNSCC's multiple mutations in a genetically complex landscape makes it difficult for one targeted therapy to have sustained efficacy. Cancers defined by carcinogen-induced genomic chaos, such as UV-induced melanoma or tobaccorelated HNSCC, are driven by a multitude of competing molecular pathways, and are thus some of the most challenging to address with targeted therapies [5]. Efficacy of targeted therapies may be confounded by the presence of coexisting tumor cell populations (clones), each with its own related but genetically distinct profile [6].

Nevertheless, potentially targetable (actionable) genomic alterations are constantly being discovered and investigated [7]. Current efforts are directed at understanding not just single gene alterations within tumor types but multi-gene expression signatures to identify functionally relevant and potentially actionable pathways. The incorporation of RNA sequencing and proteomic techniques may one day add another layer of complexity and understanding. As more tumors are sequenced, drug development expands, and our understanding of molecular pathways improves new targets and drugs will doubtless be identified. Even in the absence of actionable alterations, genetic analyses can produce a list of predictive biomarkers that can provide important prognostic information.

This review focuses on targeted therapies aimed at molecular pathways most frequently perturbed in HNSCC that have been investigated or are of potential interest in the treatment of recurrent/metastatic (R/M) HNSCC.

\section{EGFR Pathway}

EGFR is a member of the ErbB family of receptor tyrosine kinases that includes EGFR (ErbB-1), HER2/neu (ErbB-2), Her 3 (ErbB-3), and Her 4 (ErbB-4). Activation of these receptors initiates a signal transduction cascade via two primary pathways: RAS/RAF/MEK/ERK (MAPK/ERK) and PI3K/AKT/mTOR. Through complex mechanisms reviewed elsewhere, perturbed activation leads to dysregulation of the cell cycle and decreasing apoptosis while increasing DNA synthesis and cellular proliferation, leading to uncontrolled growth. 
EGFR is overexpressed in $>90 \%$ of HNSCC tumors [8]. EGFR gene amplification or high polysomy is common, seen in 58\% of HNSCC as evaluated by fluorescence in situ hybridization (FISH) [9]. Other studies report a 17\% rate of increase copy number of EGFR [10]. Studies indicate that an increased copy number of EGFR correlates with poor prognosis $[9,10]$. EGFR overexpression is linked to worse outcomes including shorter relapse-free and overall survival (OS) [11]. However, increased expression does not necessarily predict response to EGFRdirected therapy [12].

Targeted therapies against EGFR include monoclonal antibodies (mAb) that block the extracellular ligand-binding domain and tyrosine kinase inhibitors (TKIs) that prevent activation of these receptors within the cytoplasm. Cetuximab has been the most widely used targeted therapy in HNSCC. In addition to cetuximab, monoclonal antibodies targeting the ErbB pathway include panitumumab, zalutumumab, nimotuzumab, and trastuzumab whereas EGFR TKIs include gefitinib, erlotinib, lapatinib, and afatinib (Table 18.1).

\section{Cetuximab}

Cetuximab is a chimeric monoclonal antibody against EGFR. Until the introduction of immune checkpoint inhibitors cetuximab was the only molecularly targeted therapy with FDA approval for HNSCC. It was first approved for colorectal cancer in

Table 18.1 ErbB Pathway Targeted Therapies and FDA approval

\begin{tabular}{l|l|l|l}
\hline Drug & Mechanism & Cancer Type & FDA approval \\
\hline Cetuximab & EGFR Ab & $\begin{array}{l}\text { HNSCC, } \\
\text { colorectal }\end{array}$ & 2006 \\
\hline Panitumumab & EGFR Ab & Colorectal & 2006 \\
\hline Zalutumumab & EGFR Ab & - & None \\
\hline Nimotuzumab & EGFR Ab & HNSCC & None $*$ \\
\hline Matuzumab & EGFR Ab & - & None \\
\hline Trastuzumab & Her2/neu Ab & Breast & 1998 \\
\hline Duligotuzumab & EGFR + HER3 Ab & - & None \\
\hline Patritumumab & HER3 Ab & - & None \\
\hline Dacomitinib & TKI against EGFR + HER2 + HER4 & - & - \\
\hline Gefitinib & TKI against EGFR (reversible binding) & NSCLC & $2003-2005$, \\
\hline Erlotinib & TKI against EGFR (reversible binding) & $\begin{array}{l}\text { NSCLC, } \\
\text { pancreatic }\end{array}$ & 2015 \\
\hline Lapatinib & $\begin{array}{l}\text { TKI against EGFR + Her2/neu (reversible } \\
\text { binding) }\end{array}$ & Breast & 2007 \\
\hline Afatinib & $\begin{array}{l}\text { TKI against EGFR + Her2/neu + Her4 } \\
\text { (irreversible binding) }\end{array}$ & NSCLC & 2013 \\
\hline
\end{tabular}

*approved for HNSCC in other countries 
2004. In March 2006 cetuximab was approved to be used concomitantly with radiation in the definitive treatment of locally advanced HNSCC or as a single agent in patients who had failed previous platinum-based chemotherapy [13]. In 2011, it obtained approval for first-line use in the R/M setting in combination with chemotherapy. The EXTREME study investigated standard of care chemotherapy with cisplatin (or carboplatin) plus 5-fluorouracil with or without cetuximab. It demonstrated prolonged OS with the addition of cetuximab (10.1 months to 7.4 months, HR $0.8, p=0.04)$ as well as improved progression-free survival (PFS) and objective response rate (ORR) [14]. In 2019, data was published from the RTOG 1016 trial comparing concurrent chemoradiation with cisplatin versus cetuximab in HPVpositive oropharyngeal carcinoma. After a median follow up of 4.5 years cetuximab did not meet the pre-specified non-inferiority OS endpoint. Five-year OS was significantly worse for the cetuximab arm $77.9 \%$ than for the cisplatin arm 84.6\% (two-sided 95\% CI 1.03-2.05, log rank p = 0.0163) [15]. The De-ESCALaTE phase III trial randomized HPV positive low risk oropharyngeal cancer patients (nonsmokers or like time smokers with a smoking history of less than 10 pack years) to receive either cetuximab or cisplatin with radiation therapy. The primary outcome of overall severe toxicity events at 24 months did not differ significantly between the 2 groups (mean number of events per patient 4.8 with cisplatin versus 4.8 with cetuximab $\mathrm{p}=0.49$ ). Efficacy outcomes favored cisplatin: 2 -year OS 97.5 vs $89.4 \%$ HR 5 (1.7-14.7) and 2-year recurrence 6\% vs 16.1\% HR 3.4 (1.6-7.2) [16]. Further development of cetuximab in HNSCC may be in combination regimens rather than alone as a radiation sensitizer. In R/M HNSCC, the combination of cetuximab with immunotherapy or other novel approaches remains of interest.

\section{Other ErbB Antibodies}

Panitumumab, another monoclonal antibody against EGFR, did not produce efficacy results sufficient to gain regulatory approval in HNSCC. Panitumumab had low single-agent activity in recurrent/metastatic $\operatorname{HNSCC}[17,18]$, whereas its addition to cisplatin and 5-FU did not result in statistically significant OS benefit in a phase III trial (SPECTRUM). The phase III SPECTRUM trial was similar in design to the EXTREME trial with some notable differences: carboplatin was allowed in SPECTRUM only after renal impairment or neurologic toxicity, maintenance panitumumab was not mandatory, EXTREME was conducted in Europe while SPECTRUM was a global trial, and the minority of patients had undergone prior treatment for locally advanced HNSCC in EXTREME (38\%) while they represented the majority in SPECTRUM (81\%).The addition of panitumumab to cisplatin and fluorouracil improved PFS (median PFS 5.8 vs 4.6 months, HR 0.78, $\mathrm{p}=0.004$ ) but not OS (median OS 11.1 months versus 9.0 months, HR 0.873 , $\mathrm{p}=0.1403$ ), which was the primary endpoint [19]. In subset analysis, panitumumab improved OS in patients with p16 negative tumors (11.7 vs 8.6 months, HR 0.73 , $\mathrm{p}=0.0115)[19]$. 


\section{TKIs against ErbB}

Tyrosine Kinase Inhibitors (TKIs) against ErbB have been approved for other solid tumor types, but have had disappointing efficacy in HNSCC (erlotinib, gefitinib, lapatinib). Oral afatinib was compared to intravenous weekly methotrexate as second-line treatment for patients with recurrent/metastatic HNSCC after platinumbased therapy in two phase III clinical trials. In the global LUX-Head \& Neck 1 study, there was a modest but significant improvement in median PFS favoring afatinib (2.6 vs 1.7 months, $\mathrm{p}=0.03$ ) that did not translate into an OS benefit [20]. Similar results were obtained in the subsequent LUX-Head \& Neck 3 study that compared afatinib with methotrexate in Asian patients [21].

\section{Future Research into ErbB Targeting}

At present, there are no robust predictive biomarkers of response to ErbB targeted therapies in HNSCC [22]. Despite frequent overexpression of the receptor protein, mutations in the EGFR gene occur with low frequency (16\% in HPV negative HNSCC according to TCGA) and sequencing of HNSCC tumors has not demonstrated recurrent EGFR mutations. As opposed to NSCLC where clusters of mutations within exons 18-21 (tyrosine kinase domain) are seen, the mutations in HNSCC are more dispersed [23]. This may potentially explain the modest benefit of ErbB targeted therapies seen in HNSCC as compared to NSCLC [5].

Another hypothesis for limited efficacy of these agents is the presence of EGFRvIII mutation that leads to constitutive activation of the receptor independent of ligand binding. These patients would not be responsive to ErbB targeted therapy. This mutation was previously reported to be as high as $42 \%$ in HNSCC, although more recent reports suggests this is uncommon $(<1 \%)[3,24]$. This discrepancy may be attributable to difficulty in EGFRvIII detection using RNA sequencing [25].

Increased EGFR copy number is generally acknowledged as a poor prognosticator in HNSCC. In a post hoc analysis of the EXTREME trial, EGFR copy number was elevated in $40 \%$ of patients but was not found to be a predictive biomarker for the efficacy of cetuximab [12].

In colorectal cancer, RAS mutations are a predictive biomarker for cetuximab resistance, and wild type RAS status is confirmed prior to delivery of cetuximab for colorectal cancer [26]. In HNSCC RAS mutations are uncommon (4\%) in cetuximab-naive HPV negative HNSCC. However, acquisition of RAS mutations during cetuximab treatment may be common and associated with progressive disease [27]. In addition, multiple other mechanisms of resistance to ErbB targeted therapies have been described, such as downstream mutations in the PI3K/AKT/ mTOR pathway [28].

Given the lack of predictive biomarkers, choosing which patients will derive the most significant benefit from ErbB targeted therapy is difficult. Further research 
into predictive biomarkers of cetuximab efficacy may help to appropriately select patients that can benefit from this agent in future trials. Cetuximab-mediated tumor immunogenicity through antibody-dependent cellular toxicity (ADCC) has led to enthusiasm with combined approaches involving immunotherapy, e.g. combination regimens with avelumab or monalizumab [29].

\section{PI3K/AKT/mTOR Pathway}

The PI3K/AKT/mTOR pathway is a critical intracellular cascade important in cell cycle regulation, proliferation, motility, and survival. It is the most frequently dysregulated pathways in HNSCC on both a genomic and proteomic level [3, 30]. HPV positive oropharyngeal squamous cell carcinoma (OPSCC) commonly has helical domain mutations in PIK3CA. PIK3CA is an oncogene that encodes one subunit of the enzyme PI3K, a protein kinase that phosphorylates many downstream signaling proteins including AKT. PTEN is a tumor suppressor gene that encodes the PTEN protein which is a phosphatase that antagonizes PI3K signaling.

mTOR inhibitors were the first agents in this pathway to be investigated. Rapamycin, everolimus and temsirolimus are non-selective inhibitors that demonstrated limited efficacy as solo agents with significant toxicity. Preclinical studies demonstrated that mTOR inhibitors may overcome resistance to EGFR blockade and improve the efficacy of ErbB pathway agents [29]. A phase II study of temsirolimus and erlotinib for platinum-refractory R/M HNSCC was closed early because 6 out of 12 patients withdrew within 6 weeks due to toxicity or death [31]. Another phase II study of everolimus plus erlotinib failed to demonstrate a benefit in platinum-resistant R/M HNSCC despite a reasonable toxicity profile [32]. A multicenter randomized phase II study of temsirolimus with or without cetuximab randomized 80 patients with R/M HNSCC who failed a previous EGFR-based therapy (MAESTROHN, NCT01256385). There was no difference in the primary outcome of mPFS (3.5 vs 3.5 months) [33].

Buparlisib is a pan-class 1 phosphoinositide 3-kinase (PI3K) inhibitor. In a multicenter, double blind, placebo controlled phase II trial of 158 patients (BERIL-1), buparlisib + paclitaxel was superior to paclitaxel alone in the 2 nd line treatment of R/M HNSCC (median PFS 4.6 vs 3.5 months, HR 0.65, one sided p = 0.01) [34]. There was also a benefit in the secondary endpoint of OS (10.4 vs 6.5 months, onesided $\mathrm{p}=0.04)$. This trial demonstrated that response to buparlisib was not contingent on dysregulation of the PI3K/AKT/mTOR pathway via PIK3CA mutations or loss of PTEN expression (both of which were infrequent 1-13\%). Thus, a phase II trial of buparlisib monotherapy was conducted in patients with refractory HNSCC who had progressed after both platinum and cetuximab. Patients were enrolled in parallel cohorts based on the presence or absence of PIK3CA mutations in exons 9 or 20. The PIK3CA mutated cohort was prematurely closed due to slow accrual and limited activity was seen in either group (median PFS 1.8 months for mutated and 
1.7 months for nonmutated cohorts) [35]. A phase III trial is underway evaluating buparlisib plus paclitaxel versus paclitaxel alone for R/M HNSCC who have progressed on platinum-based chemotherapy with or without prior anti-PD1/PDL1 treatment (BURAN study). Based on this trial, this agent may potentially become a treatment of choice for those who do not respond to immunotherapy.

PX-866 is another oral, irreversible, pan-isoform inhibitor of PI3K that has been investigated in separate phase II clinical trials in combination with docetaxel or cetuximab [36, 37]. These trials have not yielded promising results so far.

\section{Cell Cycle Regulation}

Alterations in cell cycle regulatory mechanisms are common in HNSCC, especially in HPV negative tumors. Cyclin-Dependent Kinases (CDK) help regulate progression through the cell cycle. Mutations in TP53 (the most commonly mutated gene in HNSCC), CCND1 amplification, CDKN2A deletion, and p16 inactivation enable evasion of typical mitotic checkpoints. Aberrant cyclin D-dependent kinase activation leads to unregulated cell proliferation. Oral CDK4/6 inhibitors (palbociclib, ribociclib, and abemaciclib) have been evaluated in several phase 1 trials. These agents are under investigation as monotherapy or in combination with other drugs such as cetuximab or gedatolisib (PI3K/mTOR inhibitor).

A phase I trial of palbociclib in combination with cetuximab demonstrated an acceptable toxicity profile with no dose limiting toxicities and 5/9 patients showing measurable decreases in tumor target lesions [38]. A subsequent phase II trial (PALATINUS, NCT02499120) evaluated palbociclib + cetuximab and placebo + cetuximab in R/M HPV negative HNSCC. The study did not meet its primary endpoint. The median OS was 9.7 with palbociclib vs 7.8 months with placebo $(p=0.18)$. There was no difference in PFS (median PFS 3.9 vs 4.6 months, $p=0.5)$, but there were more hematologic adverse events with the addition of palbociclib [39]. Currently palbociclib is only approved for HR-positive, HER2-negative breast cancer.

Prexasertib (LY2606368) is a small molecule checkpoint kinase inhibitor against Chk1/2 which is involved in the S-G2 phase checkpoint. In a phase I trial that investigated this agent as monotherapy in 45 patients with advanced or metastatic nonhematologic cancerof whom 5 had HNSCC, there were 2 partial responses, one of which was in a patient with HNSCC [40]. There were 7 dose-limiting toxicities, all hematologic, most often transient grade 4 neutropenia. This prompted further evaluation in advanced squamous cell carcinomas [41]. Out of the 101 patients enrolled 57 had HNSCC. Median PFS was only 1.6 months for this group though there were 3 patients with a partial response. Later trials of prexasertib with chemotherapy and radiation were terminated (NCT02555644). Patient selection for CDKN2A/p16 loss may offer a route for further exploration of this target [42]. 


\section{DNA Repair Inhibitors}

DNA damage repair (DDR) inhibitors are medications that interfere with DNA repair mechanisms. These medications have been investigated as monotherapy, in combination with other cytotoxic chemotherapeutics (cisplatin), and with RT. This combination is mechanistically logical, as the initiation of DNA damage by these traditional treatments may have a more profound impact on tumor death when the repair of their damage is prevented by DDR inhibitors. As opposed to many other targeted therapies that have been used in the R/M setting, some of these agents have been investigated in the definitive setting.

Poly (ADP-ribose) polymerase (PARP) is an enzyme involved in the repair of single-stranded DNA breaks. PARP inhibitors are a class of medications that prevent the repair of this form of DNA damage. If cells with unrepaired single strand breaks proceed through mitosis, double strand DNA breaks develop, which can lead to cell death. Olaparib (AZD2281) was the first PARP inhibitor approved by the FDA in December 2014 for germline BRCA mutated ovarian cancer who had failed 3 previous chemotherapies. Rucaparib, niraparib, and talazoparib have more recently been granted FDA approval for other tumor types. No PARP inhibitors have approvals in HNSCC. Olaparib was combined with cetuximab and RT in a phase 1 trial for definitive treatment of locoregionally advanced inoperable HNSCC in smokers, and is in trials in combination with cisplatin plus RT (NCT02308072, ORCA-2) or olaparib and RT alone (NCT02229656) for definitive treatment [43].

ATM and ATR are protein kinases involved in the recognition and repair of double strand DNA breaks. ATM plays a crucial role in the G1/S cell cycle checkpoint as well as intra-S phase checkpoint. Downstream targets of ATM include CHK2 and p53 [44]. ATR is activated by single strand DNA structures that may arise at resected DNA double strand breaks or at stalled replication forks. ATR is the principal mediator of the G2/M cell cycle checkpoint as well as the intra-S phase checkpoint. Downstream targets of ATR include CHK1. Both ATM and ATR inhibitors are in clinical development: ATM- KU559403, KU60019, and KU55933 and ATR- VX970 also known as M6620, VE821, VE822, and AZD6738 also known as ceralasertib. These agents have sensitized tumor cells to radiation in vitro, but there is limited data on their efficacy in vivo $[42,45,46]$. AZD6738 was combined with the PD-L1 inhibitor durvalumab in a multicohort trial. Twenty five patients with either nonsmall cell lung cancer or HNSCC were enrolled in the trial and 1 response was seen in a HNSCC patient [47]. A phase 1 trial of the ATR inhibitor VX970 also known as M6620 in combination with cisplatin and radiation is currently underway enrolling clinical stage III or IV HNSCC (NCT02567422).

WEE1 is a tyrosine kinase involved in the phosphorylation and inactivation of cyclin dependent kinase 1 (CDK1) - bound cyclin B which results in G2 cycle arrest. AZD1775 is a WEE1 inhibitor hypothesized to target p53-mutant tumors being investigated in NCT01748825. In vivo assays have shown WEE1 inhibitor sensitizes head and neck cancer cells to NK cell lysis, potentially indicating a future role for combination with immunotherapy [48]. 
DDR inhibitors are under study as part of combination therapies in the definitive setting. Moreover, novel combinations of DDR inhibitors with immunotherapy are of interest. Future trials may bring DDR inhibitors to the forefront of HNSCC treatment.

\section{Antiangiogenesis}

Vascular endothelial growth factor (VEGF) and its tyrosine kinase receptors are involved in angiogenesis and proliferation. Treatments against this pathway include both antibodies against VEGF as well as tyrosine kinase inhibitors against VEGFR and are summarized in Table 18.2. Tumor VEGF overexpression is common in HNSCC and is an independent negative prognostic factor for survival in locoregionally advanced HNSCC $[49,50]$. Unfortunately, investigation into this class of agents for HNSCC has demonstrated limited efficacy with considerable toxicity. Mutations in the VEGF pathway have prognostic relevance, but are not predictive with regard to response to therapy.

There are currently multiple anti-angiogenic agents that have been approved by the FDA (Table 18.2). These range from ligand-directed antibodies to receptordirected antibodies to small molecule inhibitors to immunomodulatory agents. Research in HNSCC has focused on monoclonal antibodies and tyrosine kinase inhibitors (TKIs). Development of these antibodies and TKIs has occurred through monotherapy as well as though combinations with other modalities and therapeutic agents: chemotherapy, radiotherapy, molecularly targeted therapy, and more recently, immunotherapy.

Table 18.2 Selected FDA approved anti-angiogenic agents for the treatment of solid tumors

\begin{tabular}{|c|c|}
\hline Agent & Molecular Targets \\
\hline \multicolumn{2}{|c|}{ Monoclonal antibodies } \\
\hline Bevacizumab & VEGF \\
\hline Ramucirumab & VEGFR2 \\
\hline \multicolumn{2}{|l|}{ Fusion protein } \\
\hline Ziv-Aflibercept & VEGF, VEGF-B, PlGF \\
\hline \multicolumn{2}{|c|}{ Multi-kinase inhibitors } \\
\hline Sorafenib & RAF/MEK/ERK, VEGFR 1-3, PDGFR- $\beta$, c-KIT, FLT3, RET \\
\hline Sunitinib & VEGFR1 and 2 , PDGFR- $\alpha$ and $-\beta, \mathrm{c}-\mathrm{KIT}, \mathrm{RET}, \mathrm{CSF} 1 \mathrm{R}, \mathrm{FLT} 3$ \\
\hline Vandetanib & VEGFR2 and 3, EGFR, RET \\
\hline Pazopanib & VEGFR $1-3$, PDGFR- $\alpha$ and $-\beta$, FGFR- 1 and $-3, \mathrm{c}-$ KIT \\
\hline Axitinib & VEGFR $1-3$, PDGFR- $\alpha$ and $-\beta, \mathrm{c}-\mathrm{KIT}$ \\
\hline Regorafenib & VEGFR1-3 \\
\hline Lenvatinib & VEGR1-3, FGFR1-4, PDGFR- $\alpha, \mathrm{c}-\mathrm{KIT}, \mathrm{RET}$ \\
\hline Cabozatinib & VEGFR2, AXL, RET, MET, c-KIT, FLT-3 \\
\hline
\end{tabular}


When used as monotherapy in previously treated R/M HNSCC overall responses have been disappointing [51-53]. When used in combination with other therapies, such as cetuximab plus sorafenib or docetaxel plus vandetanib, there was no additional benefit in phase II randomized trials [54, 55], however, two single arm trials (one with cetuximab plus pazopanib and another with carboplatin, paclitaxel plus sorafenib) reported promising results $[62,63]$ (Table 18.3).

Bevacizumab is an antibody against VEGF-A that has been studied in the definitive setting as well as in combination with chemotherapy in R/M HNSCC (Table 18.4). In the definitive setting, the addition of bevacizumab to cetuximab, pemetrexed, and RT did not demonstrate any additional survival or disease control benefit, but did have more hemorrhagic complications [64].

E1305 was a phase III randomized trial that investigated the addition of bevacizumab to platinum doublet therapy as first-line treatment in patients with $\mathrm{R} / \mathrm{M}$

Table 18.3 VEGFR tyrosine-kinase inhibitors studied as monotherapy or combination therapy in HNSCC

\begin{tabular}{|c|c|c|c|c|c|c|}
\hline Agents & $\begin{array}{l}\text { Study Design/ } \\
\text { Phase }\end{array}$ & $\mathrm{N}$ & $\begin{array}{l}\text { Response } \\
\text { Rate }\end{array}$ & $\begin{array}{l}\text { mPFS } \\
\text { (months) }\end{array}$ & \begin{tabular}{|l}
$\begin{array}{l}\text { mOS } \\
\text { (months) }\end{array}$ \\
\end{tabular} & Reference \\
\hline $\begin{array}{l}\text { Sorafenib } 400 \mathrm{mg} \\
\text { BID }\end{array}$ & $\begin{array}{l}\text { Single arm, } \\
\text { phase II }\end{array}$ & 27 & $4 \%$ & $1.8^{*}$ & 4.2 & Elser, 2007 [56] \\
\hline $\begin{array}{l}\text { Sorafenib } 400 \mathrm{mg} \\
\text { BID }\end{array}$ & $\begin{array}{l}\text { Single arm, } \\
\text { phase II }\end{array}$ & 41 & $2 \%$ & 4 & 9 & $\begin{array}{l}\text { Williamson, } \\
2010 \text { [57] }\end{array}$ \\
\hline $\begin{array}{l}\text { Sorafenib } 400 \mathrm{mg} \\
\text { BID }\end{array}$ & $\begin{array}{l}\text { Single arm, } \\
\text { phase II }\end{array}$ & 23 & $38 \% * *$ & 3.4 & 8 & $\begin{array}{l}\text { Lalami, } 2016 \\
\text { [52] }\end{array}$ \\
\hline $\begin{array}{l}\text { Sunitinib } 37.5 \mathrm{mg} \\
\text { QD }\end{array}$ & $\begin{array}{l}\text { Single arm, } \\
\text { phase II }\end{array}$ & 38 & 3 & 2 & 3.4 & $\begin{array}{l}\text { Machiels, } 2010 \\
\text { [58] }\end{array}$ \\
\hline $\begin{array}{l}\text { Sunitinib } 50 \mathrm{mg} \\
\text { QD } 4 / 6 \text { weeks }\end{array}$ & $\begin{array}{l}\text { Single arm, } \\
\text { phase II } \\
\text { Cohort A: PS 0-1 } \\
\text { cohort B: PS } 2\end{array}$ & 22 & $\begin{array}{l}\text { A: } 8 \% \\
\text { B: } 0 \%\end{array}$ & $\begin{array}{l}\mathrm{A}: 2 * \\
\mathrm{~B}: 2.5^{*}\end{array}$ & $\begin{array}{l}\text { A: } 4.9 \\
\text { B: } 4.5\end{array}$ & $\begin{array}{l}\text { Choong, } 2010 \\
{[59]}\end{array}$ \\
\hline $\begin{array}{l}\text { Sunitinib } 50 \mathrm{mg} \\
\text { QD 4/6 weeks }\end{array}$ & $\begin{array}{l}\text { Single arm, } \\
\text { phase II }\end{array}$ & 17 & 0 & $2.3^{*}$ & 4 & $\begin{array}{l}\text { Fountzilas, } 2010 \\
{[60]}\end{array}$ \\
\hline $\begin{array}{l}\text { Axitinib } 5 \mathrm{mg} \\
\text { BID }\end{array}$ & $\begin{array}{l}\text { Single arm, } \\
\text { phase II }\end{array}$ & 30 & $7 \%$ & 3.7 & 10.9 & $\begin{array}{l}\text { Swiecicki, } 2015 \\
\text { [53] }\end{array}$ \\
\hline $\begin{array}{l}\text { Semaxinib } \\
145 \mathrm{mg} / \mathrm{m}^{2} \text { twice } \\
\text { per week }\end{array}$ & $\begin{array}{l}\text { Single arm, } \\
\text { phase II }\end{array}$ & 35 & $3 \%$ & & 6.25 & Fury, 2007 [61] \\
\hline $\begin{array}{l}\text { Cetuximab + } \\
\text { Pazopanib }\end{array}$ & $\begin{array}{l}\text { Single arm, } \\
\text { phase I }\end{array}$ & 31 & $35 \%$ & 5.3 & 9.5 & $\begin{array}{l}\text { Adkins, } 2019 \\
\text { [62] }\end{array}$ \\
\hline $\begin{array}{l}\text { Cetuximab } \\
+/- \text { sorafenib }\end{array}$ & $\begin{array}{l}\text { Randomized, } \\
\text { phase II }\end{array}$ & 55 & $8 \%$ v $8 \%$ & $3 \vee 3.2$ & 9 v 5.7 & $\begin{array}{l}\text { Gilbert, } 2015 \\
\text { [54] }\end{array}$ \\
\hline $\begin{array}{l}\text { Docetaxel } \\
+/- \text { vandetanib }\end{array}$ & $\begin{array}{l}\text { Randomized, } \\
\text { phase II }\end{array}$ & 29 & $7 \%$ v $13 \%$ & $0.75 \vee 2.1$ & 6.3 v 5.6 & $\begin{array}{l}\text { Limaye, } 2013 \\
{[55]}\end{array}$ \\
\hline $\begin{array}{l}\text { Carboplatin, } \\
\text { paclitaxel, } \\
\text { sorafenib }\end{array}$ & $\begin{array}{l}\text { Single arm, } \\
\text { phase II }\end{array}$ & 48 & $55 \%$ & 8.5 & 22.6 & $\begin{array}{l}\text { Blumenschein, } \\
2012[63]\end{array}$ \\
\hline
\end{tabular}

*TTP time to progression; **Metabolic response rate by Fluorodeoxyglucose Positron Emission Tomography; $B I D$ bis in die (two times per day); $Q D$ quaque die (one a day); $m P F S$ median Progression-Free Survival; $m O S$ median Overall Survival, PS Performance Status 
Table 18.4 Bevacizumab-containing combination therapies in R/M HNSCC

\begin{tabular}{|c|c|c|c|c|c|}
\hline $\begin{array}{l}\text { Agents Combined with } \\
\text { Bevacizumab }\end{array}$ & $\begin{array}{l}\text { Study } \\
\text { Design }\end{array}$ & Phase & $\mathrm{N}$ & $\begin{array}{l}\text { Primary Efficacy } \\
\text { Endpoint }\end{array}$ & Reference \\
\hline \multicolumn{6}{|l|}{ Chemotherapy } \\
\hline Pemetrexed + bevacizumab & Single arm & II & 47 & mTTP 5 months & $\begin{array}{l}\text { Argiris, } 2011 \\
{[65]}\end{array}$ \\
\hline $\begin{array}{l}\text { Investigator's choice: } \\
\text { Cisplatin+5-FU, } \\
\text { Cisplatin+docetaxel, } \\
\text { Carboplatin+5-FU, or } \\
\text { Carboplatin+ docetaxel } \\
\text { +/- Bevacizumab }\end{array}$ & Randomized & III & 403 & $\begin{array}{l}\text { mOS } \\
12.6 \text { months with } \\
\text { bevacizumab } \\
11 \text { months without } \\
\text { bevacizumab } \\
(\mathrm{p}=0.13)\end{array}$ & $\begin{array}{l}\text { Argiris, } 2019 \\
{[66]}\end{array}$ \\
\hline \multicolumn{6}{|l|}{ EGFR inhibitor } \\
\hline Cetuximab + bevacizumab & Single arm & II & 46 & RR $16 \%$ & $\begin{array}{l}\text { Argiris, } 2013 \\
\text { [67] }\end{array}$ \\
\hline Erlotinib + bevacizumab & Single arm & I/II & $\begin{array}{l}10 \\
/ 48\end{array}$ & mPFS 4.1 months & $\begin{array}{l}\text { Cohen, } 2009 \\
\text { [68] }\end{array}$ \\
\hline
\end{tabular}

$m T T P$ median Time To Progression, $m O S$ median Overall Survival, $R R$ overall Response Pate, $m P F S$ median Progression-Free Survival

HNSCC. A total of 403 patients were enrolled in multiple centers. With the addition of bevacizumab there was an improvement in objective response rate (36\% vs $25 \%$, $\mathrm{p}=0.01$ ) and PFS (median PFS 6.1 months with bevacizumab vs 4.4 months without bevacizumab, $\mathrm{p}=0.001$ ) but not OS (median OS 12.6 months with bevacizumab vs 11 months without bevacizumab, $\mathrm{p}=0.13$ ), which was the primary endpoint [66]. Although the primary endpoint of the study was not met, there was a numerical overall survival advantage at 2,3 and 4 years in the bevacizumab arm $(25 \%$ vs $18 \%$ at 2 years, $16 \%$ vs $10 \%$ at 3 years, and $12 \%$ vs $6 \%$ at 4 years for chemotherapy plus bevacizumab versus chemotherapy alone). Patients experienced more treatment-related toxicities with bevacizumab, particularly grade 3-5 bleeding. While this study provided evidence of improved antitumor activity with the addition of an anti-angiogenic agent to chemotherapy, no randomized trials have shown survival benefit with this approach in HNSCC. Studies with better-tolerated anti-angiogenic agents in combination with chemotherapy or other targeted agents should be considered. It is likely that better patient selection based on molecular biomarkers will optimize outcomes. Moreover, combination of anti-angiogenic agents with immunotherapy could improve anti-tumor efficacy due to synergist effects on the immune response. A randomized phase III trial of pembrolizumab with or without lenvatinib as first-line treatment for R/M HNSCC is currently ongoing (ClinicalTrials.gov Identifier: NCT04199104).

\section{RAS-RAF-MEK-ERK Pathway}

The RAS-RAF-MEK-ERK pathway (synonymous with MAPK/ERK pathway) is a mitogenic signal transduction cascade that leads to progression through the cell cycle and mitosis. The RAS family of genes (HRAS, KRAS, NRAS) encode 
GTPase proteins that are involved in cellular signal transduction leading to cell growth, differentiation, and survival. RAS signals upstream of the PI3K and MAPK pathways. In human cancers RAS are commonly mutated oncogenes. However, in HNSCC RAS is mutated in only $4-6 \%$ of tumors $[69,70]$. RAS mutations are associated with high levels of EGFR resistance (EGFR acts upstream of RAS). In vitro, PI3K inhibitors (which act downstream of RAS) have demonstrated efficacy in HRAS mutant HNSCC [69].

Tipifarnib is a farnesyltransferase inhibitor. This enzyme catalyzes the binding of farnesyl groups to RAS proteins, enabling them to localize to the cell membrane where they can exert their oncogenic effects. A phase II trial of tipifarnib in patients with HRAS mutant HNSCC reported partial responses in 9/18 evaluable patients (objective response rate of 50\%) [71-73]. The median duration of response was 14.7 months and the median PFS was 5.9 months. Interestingly, the enrolled patients had an estimated median PFS of 2.8 months on the prior line of therapy. Additional studies are ongoing with this agent as monotherapy and in combination with chemotherapy.

Agents also in this pathway include dabrafenib (BRAF inhibitor) and trametinib (MEK inhibitor) which have been most commonly used in BRAF mutant melanoma. BRAF mutations are not common in HNSCC, as low as 3\% [74] but have proven to be highly targetable including in cancers traditionally refractory to other treatments [75]. The specific efficacy of these agents in HNSCC is as yet unproven.

\section{FGFR}

Targeting the Fibroblast Growth Factor Receptor (FGFR) pathway has very recently been generating enthusiasm in several cancer types, including HNSCC. FGFR is made up of five isoforms, FGFR1-4 being RTKs and FGFR5 lacking an intracellular domain. Downstream signaling of FGFR occurs through several pathways including MAPK/ERK, PI3K/AKT/mTOR, PLC $\gamma$, and STAT leading to proliferation, survival, angiogenesis, and migration [76]. Rogaratinib is an adenosine triphosphate (ATP) competitive inhibitor of FGFR 1-4 [77]. Erdafitinib, another pan-FGFR inhibitor, has been used to treat urothelial cancer, where FGFR mutations are present in 32\% [78].

FGFR1 mutations are present in about 5-10\% of HPV negative HNSCC while FGFR3 are present in 1-12\% HPV positive HNSCC. Bayer, the manufacturer of the rogaratinib, recommends using a mRNA based FGFR assay (RNA scope) to preselect patients that may derive benefit. This assay is being used to determine eligibility for rogaratinib treatment in the EORTC UPSTREAM trial, discussed later. FGFR1-3 mRNA positivity was found in $56.5 \%$ of a cohort of 46 HNSCC patients [79]. However, patients with high mRNA levels do not necessarily have genetic FGFR alterations [80]. There is preclinical data that demonstrates that FGFR signaling may mediate cisplatin resistance in HNSCC [81]. 


\section{Neurotrophic Tyrosine Kinase Receptor Family}

The Neurotrophic Tyrosine Kinase Receptor (NTRK) family is synonymous with Tropomyosin receptor kinase (Trk). The NTRK1 gene encodes the Tropomyosin receptor kinase A (TrkA) which binds neurotrophin (nerve growth factor). This signaling pathway is important for neuronal differentiation and avoidance of programmed cell death. Tropomyosin-related kinase B (TrkB) serves as a receptor for brain-derived neurotrophic factor (BDNF) and for neurotrophic factor 4 (NT4), and has been found to be a potentially important mediator of the invasive properties of HNSCC and a mediator of the epithelial-mesenchymal transition (EMT). In particular, TrkB and BDNF are expressed in $>50 \%$ of HNSCC tumors, and stimulation of this pathway increases the migratory and invasive properties of HNSCC [82]. The BDNF-TrkB signaling pathway has been implicated in platinum resistance in HNSCC [83].

It is now appreciated that fusions of NTRK1, NTRK2, and NTRK3 represent oncogenic alterations in multiple tumor types. The FDA granted accelerated approval for larotrectinib, an oral TRK inhibitor, in November 2018 for patients with solid tumors harboring an NTRK gene fusion. This approval was based on pooled results of three trials (LOXO-TRK-14001, SCOUT, and NAVIGATE) that included a combined 55 adults and pediatric patients with NTRK gene fusions [84]. The associated cancers spanned many pathologies including soft tissue sarcoma $(20 \%)$, salivary gland cancer $(22 \%)$, infantile fibrosarcoma (13\%), thyroid cancer (9\%), lung cancer, melanoma, colon cancer, gastrointestinal stromal tumor, appendix cancer, breast cancer and pancreatic cancer. Results from this pooled analysis showed a $75 \%$ overall response rate, a $22 \%$ complete response rate and a $53 \%$ partial response rate across these various tumor types. This approval was unique in that it was the second histology agnostic approval ever granted by the FDA, and the first ever for a specific genomic aberration. The first histology agnostic approval was pembrolizumab in May 2017.

Entrectinib is another exciting agent in this class [85]. In a pooled analysis integrating data from three ongoing phase 1 or 2 clinical trials (ALKA-372-001, STARTRK-1 and STARTRK-2) 57\% of patients had an objective response, $7 \%$ of which was a complete response. LOXO-195 and TPX-0005 are 2nd generation TRK inhibitors that are being investigated in patients who have developed resistance to other TRK therapies [86].

These agents are unlikely to have significant impact in HNSCC, as NTRK fusion mutations are rare in HNSCC. However, the development of this targeted therapy for this specific genomic aberration, its markedly profound efficacy, as well as the approval process and indication represents an exciting precedent for future drug development and clinical trial design. 


\section{Implications for Clinical Trial Design}

Clinical trial design has adapted to the changing landscape of cancer genomics. The disappointing efficacy of targeted therapies in HNSCC may be due to the lack of molecular selection. Refinement in research strategy may lead to improved outcomes. Basket trials include patients from multiple different cancer pathologies and organ systems that are all united by a common mutation. These trials test the effect of one targeted therapy designed to counteract this specific mutation that is shared by all eligible patients, such as the larotrectinib in LOXO-TRK-14001 trial. These studies greatly increase the number of patients who are able to receive and potentially benefit from new drugs. Umbrella trials, on the other hand, include patients all of the same tumor type (i.e. HNSCC). Patients are screened for genomic aberrations, and may be eligible for different treatment arms of the study depending on the genetic profile of their tumor. Umbrella trials are designed to test the impact of different drugs on different mutations in a single type of cancer. This strategy allows for biomarker enrichment in each study arm. Finally, "super umbrella" trials are umbrella trials that include patients with multiple histologies.

The National Cancer Institute's (NCI's) Molecular Analysis for Therapy Choice (MATCH) (NCT02465060) initiative is an ongoing phase II super umbrella trial. This tissue of origin agnostic trial has 35 possible treatment subprotocols based on the genetic abnormality specific to a patient's tumor. New subprotocols can be added as targets and drugs become available. The American Society of Clinical Oncology (ASCO) has a likeminded trial entitled Targeted Agent and Profiling Utilization Registry (TAPUR). This nonrandomized trial is also openly recruiting and uses molecular profile testing to decide which FDA-approved targeted therapy may provide clinical benefit to patients who have failed standard first-line treatment. These trials can help enroll large number of patients to assess efficacy as well as develop hypotheses for future clinical trials.

EORTC 1559 (UPSTREAM) is the first European biomarker driven umbrella trial in R/M HNSCC which opened in December, 2017 [61]. This trial enrolls patients with R/M SCC progressing after first-line platinum-based chemotherapy. Patients are tested for 13 oncogenes and tumor suppressor genes: EGFR, HER2, TP53, PIK3CA, CCND1, NRAS, KRAS, HRAS, PTEN, FGFR1, FGFR2, FGFR3, and cMET. Based on the molecular alterations identified in the tumor, patients may be eligible for one of six different biomarker driven treatment cohorts. They may be eligible for targeted therapies including afatinib (ErB TKI), palbociclib (CDK 4/6 inhibitor), niraparib (PARP inhibitor), or rogaratinib (FGFR inhibitor). In patients without any actionable mutation, they are enrolled in an immunotherapy cohort (monalizumab \pm durvalumab). Upfront selection of patients/tumors with actionable targets and matching them with the appropriate targeted therapies may improve patients' outcomes. This strategy of designing trials with molecularly enriched patient populations will hopefully demonstrate improved efficacy for molecularly targeted therapies. 
In November 2017 the Centers for Medicare and Medicaid Services (CMS) in the US released a position statement on Next Generation Sequencing (NGS). NGS will be covered by insurance as a diagnostic laboratory test for patients with recurrent, metastatic, or advanced stage IV cancer who are seeking further cancer treatment. There are several predefined reporting and registry criteria that both the test and the testing center must adhere to in order to receive payment for NGS. This decision helps push forward a major shift in the exploration of further treatment for patients who may have limited and/or disappointing treatment options. NGS enables a more in depth understanding of specific drivers of a patient's cancer, and allows for opportunities to employ targeted therapies directed at these mutated pathways.

Even when an actionable mutation is discovered, treatment response is often seen for a finite amount of time. Cancers are heterogeneous populations of cells and may evolve under pressures of drug treatment [6]. Testing and retesting of the genomic composition of refractory cancers will be necessary in order to understand how and why resistance mechanisms to targeted therapies develop. When discordant treatment responses are seen in different metastatic lesions within the same patient, biopsies can reveal a different genetic make-up in these separate tumors. New strategies, and in some cases common pathway dual inhibitor therapies, will need to be engineered in order to best prevent mutational escape.

\section{Conclusions}

The molecular landscape of HNSCC is complex and has yielded relatively few targetable mutations. Our current understanding has led to clinical investigation of several agents targeting EGFR, PI3K, VEGF/VEGFR, RAS and other pathways with variable success. Careful patient selection may provide a path forward. Recent successes with tipifarnib monotherapy in selected patients harboring HRAS mutant tumors as well as the combination of buparlisib plus paclitaxel in unselected tumors underscore that the study of novel targets, targeted agents, and biomarkers must continue in HNSCC.

\section{References}

1. The Cancer Genome Atlas - About the Program-National Cancer Institute [Available from: https://www.cancer.gov/about-nci/organization/ccg/research/structural-genomics/tcga/history.

2. Boland GM, Piha-Paul SA, Subbiah V, Routbort M, Herbrich SM, Baggerly K, et al. Clinical next generation sequencing to identify actionable aberrations in a phase I program. Oncotarget. 2015;6(24):20099-110.

3. Comprehensive genomic characterization of head and neck squamous cell carcinomas. Nature. 2015;517(7536):576-82. 
4. Klussmann JP, Mooren JJ, Lehnen M, Claessen SM, Stenner M, Huebbers CU, et al. Genetic signatures of HPV-related and unrelated oropharyngeal carcinoma and their prognostic implications. Clin Cancer Res. 2009;15(5):1779-86.

5. Afghahi A, Sledge GW Jr. Targeted therapy for cancer in the genomic era. Cancer journal (Sudbury, Mass). 2015;21(4):294-8.

6. Carr TH, McEwen R, Dougherty B, Johnson JH, Dry JR, Lai Z, et al. Defining actionable mutations for oncology therapeutic development. Nat Rev Cancer. 2016;16(5):319-29.

7. Dienstmann R, Jang IS, Bot B, Friend S, Guinney J. Database of genomic biomarkers for cancer drugs and clinical targetability in solid tumors. Cancer Discov. 2015;5(2):118-23.

8. Dassonville O, Formento JL, Francoual M, Ramaioli A, Santini J, Schneider M, et al. Expression of epidermal growth factor receptor and survival in upper aerodigestive tract cancer. J Clin Oncol. 1993;11(10):1873-8.

9. Chung CH, Ely K, McGavran L, Varella-Garcia M, Parker J, Parker N, et al. Increased epidermal growth factor receptor gene copy number is associated with poor prognosis in head and neck squamous cell carcinomas. J Clin Oncol. 2006;24(25):4170-6.

10. Temam S, Kawaguchi H, El-Naggar AK, Jelinek J, Tang H, Liu DD, et al. Epidermal growth factor receptor copy number alterations correlate with poor clinical outcome in patients with head and neck squamous cancer. J Clin Oncol. 2007;25(16):2164-70.

11. Rubin Grandis J, Melhem MF, Gooding WE, Day R, Holst VA, Wagener MM, et al. Levels of TGF-alpha and EGFR protein in head and neck squamous cell carcinoma and patient survival. J Natl Cancer Inst. 1998;90(11):824-32.

12. Licitra L, Mesia R, Rivera F, Remenar E, Hitt R, Erfan J, et al. Evaluation of EGFR gene copy number as a predictive biomarker for the efficacy of cetuximab in combination with chemotherapy in the first-line treatment of recurrent and/or metastatic squamous cell carcinoma of the head and neck: EXTREME study. Ann Oncol. 2011;22(5):1078-87.

13. Bonner JA, Harari PM, Giralt J, Azarnia N, Shin DM, Cohen RB, et al. Radiotherapy plus cetuximab for squamous-cell carcinoma of the head and neck. N Engl J Med. 2006;354(6):567-78.

14. Vermorken JB, Mesia R, Rivera F, Remenar E, Kawecki A, Rottey S, et al. Platinum-based chemotherapy plus cetuximab in head and neck cancer. N Engl J Med. 2008;359(11):1116-27.

15. Gillison ML, Trotti AM, Harris J, Eisbruch A, Harari PM, Adelstein DJ, et al. Radiotherapy plus cetuximab or cisplatin in human papillomavirus-positive oropharyngeal cancer (NRG oncology RTOG 1016): a randomised, multicentre, non-inferiority trial. Lancet. 2019;393(10166):40-50.

16. Mehanna H, Robinson M, Hartley A, Kong A, Foran B, Fulton-Lieuw T, et al. Radiotherapy plus cisplatin or cetuximab in low-risk human papillomavirus-positive oropharyngeal cancer (De-ESCALaTE HPV): an open-label randomised controlled phase 3 trial. Lancet. 2019;393(10166):51-60.

17. Rischin D, Spigel DR, Adkins D, Wein R, Arnold S, Singhal N, et al. PRISM: phase 2 trial with panitumumab monotherapy as second-line treatment in patients with recurrent or metastatic squamous cell carcinoma of the head and neck. Head Neck. 2016;38(Suppl 1):E1756-61.

18. Siano M, Molinari F, Martin V, Mach N, Fruh M, Freguia S, et al. Multicenter phase II study of Panitumumab in platinum pretreated, advanced head and neck squamous cell cancer. Oncologist. 2017;22(7):782-e70.

19. Vermorken JB, Stohlmacher-Williams J, Davidenko I, Licitra L, Winquist E, Villanueva C, et al. Cisplatin and fluorouracil with or without panitumumab in patients with recurrent or metastatic squamous-cell carcinoma of the head and neck (SPECTRUM): an open-label phase 3 randomised trial. Lancet Oncol. 2013;14(8):697-710.

20. Machiels JP, Haddad RI, Fayette J, Licitra LF, Tahara M, Vermorken JB, et al. Afatinib versus methotrexate as second-line treatment in patients with recurrent or metastatic squamous-cell carcinoma of the head and neck progressing on or after platinum-based therapy (LUX-Head \& Neck 1): an open-label, randomised phase 3 trial. Lancet Oncol. 2015;16(5):583-94.

21. Guo Y, Ahn MJ, Chan A, Wang CH, Kang JH, Kim SB, et al. Afatinib versus methotrexate as second-line treatment in Asian patients with recurrent or metastatic squamous cell carcinoma 
of the head and neck progressing on or after platinum-based therapy (LUX-Head \& Neck 3): an open-label, randomised phase III trial. Ann Oncol. 2019;30(11):1831-9.

22. Boeckx C, Weyn C, Vanden Bempt I, Deschoolmeester V, Wouters A, Specenier P, et al. Mutation analysis of genes in the EGFR pathway in head and neck cancer patients: implications for anti-EGFR treatment response. BMC Res Notes. 2014;7:337.

23. Lawrence MS, Stojanov P, Mermel CH, Robinson JT, Garraway LA, Golub TR, et al. Discovery and saturation analysis of cancer genes across 21 tumour types. Nature. 2014;505(7484):495-501.

24. Sok JC, Coppelli FM, Thomas SM, Lango MN, Xi S, Hunt JL, et al. Mutant epidermal growth factor receptor (EGFRvIII) contributes to head and neck cancer growth and resistance to EGFR targeting. Clin Cancer Res. 2006;12(17):5064-73.

25. Wheeler SE, Egloff AM, Wang L, James CD, Hammerman PS, Grandis JR. Challenges in EGFRvIII detection in head and neck squamous cell carcinoma. PLoS One. 2015;10(2):e0117781.

26. Bokemeyer C, Van Cutsem E, Rougier P, Ciardiello F, Heeger S, Schlichting M, et al. Addition of cetuximab to chemotherapy as first-line treatment for KRAS wild-type metastatic colorectal cancer: pooled analysis of the CRYSTAL and OPUS randomised clinical trials. Eur J Cancer. 2012;48(10):1466-75.

27. Braig F, Voigtlaender M, Schieferdecker A, Busch CJ, Laban S, Grob T, et al. Liquid biopsy monitoring uncovers acquired RAS-mediated resistance to cetuximab in a substantial proportion of patients with head and neck squamous cell carcinoma. Oncotarget. 2016;7(28):42988-95.

28. Brand TM, Iida M, Wheeler DL. Molecular mechanisms of resistance to the EGFR monoclonal antibody cetuximab. Cancer Biol Ther. 2011;11(9):777-92.

29. Taberna M, Oliva M, Mesia R. Cetuximab-containing combinations in locally advanced and recurrent or metastatic head and neck squamous cell carcinoma. Front Oncol. 2019;9:383.

30. Michmerhuizen NL, Birkeland AC, Bradford CR, Brenner JC. Genetic determinants in head and neck squamous cell carcinoma and their influence on global personalized medicine. Genes Cancer. 2016;7(5-6):182-200.

31. Bauman JE, Arias-Pulido H, Lee SJ, Fekrazad MH, Ozawa H, Fertig E, et al. A phase II study of temsirolimus and erlotinib in patients with recurrent and/or metastatic, platinum-refractory head and neck squamous cell carcinoma. Oral Oncol. 2013;49(5):461-7.

32. Massarelli E, Lin H, Ginsberg LE, Tran HT, Lee JJ, Canales JR, et al. Phase II trial of everolimus and erlotinib in patients with platinum-resistant recurrent and/or metastatic head and neck squamous cell carcinoma. Ann Oncol. 2015;26(7):1476-80.

33. Seiwert TY, Kochanny S, Wood K, Worden FP, Adkins D, Wade JL, et al. A randomized phase 2 study of temsirolimus and cetuximab versus temsirolimus alone in recurrent/metastatic, cetuximab-resistant head and neck cancer: The MAESTRO study. Cancer. 2020.

34. Soulieres D, Faivre S, Mesia R, Remenar E, Li SH, Karpenko A, et al. Buparlisib and paclitaxel in patients with platinum-pretreated recurrent or metastatic squamous cell carcinoma of the head and neck (BERIL-1): a randomised, double-blind, placebo-controlled phase 2 trial. Lancet Oncol. 2017;18(3):323-35.

35. Fayette J, Digue L, Ségura-Ferlay C, Treilleux I, Wang Q, Lefebvre G, et al. Buparlisib (BKM120) in refractory head and neck squamous cell carcinoma harbouring or not a PI3KCA mutation: a phase II multicenter trial. Ann Oncol. 2018;30(suppl_5):449-74.

36. Jimeno A, Bauman JE, Weissman C, Adkins D, Schnadig I, Beauregard P, et al. A randomized, phase 2 trial of docetaxel with or without PX-866, an irreversible oral phosphatidylinositol 3-kinase inhibitor, in patients with relapsed or metastatic head and neck squamous cell cancer. Oral Oncol. 2015;51(4):383-8.

37. Jimeno A, Shirai K, Choi M, Laskin J, Kochenderfer M, Spira A, et al. A randomized, phase II trial of cetuximab with or without PX-866, an irreversible oral phosphatidylinositol 3-kinase inhibitor, in patients with relapsed or metastatic head and neck squamous cell cancer. Ann Oncol. 2015;26(3):556-61. 
38. Michel L, Ley J, Wildes TM, Schaffer A, Robinson A, Chun SE, et al. Phase I trial of palbociclib, a selective cyclin dependent kinase 4/6 inhibitor, in combination with cetuximab in patients with recurrent/metastatic head and neck squamous cell carcinoma. Oral Oncol. 2016;58:41-8.

39. Adkins D, Ley J, Neupane P, Worden F, Sacco AG, Palka K, et al. Palbociclib and cetuximab in platinum-resistant and in cetuximab-resistant human papillomavirus-unrelated head and neck cancer: a multicentre, multigroup, phase 2 trial. Lancet Oncol. 2019;20(9):1295-305.

40. Hong D, Infante J, Janku F, Jones S, Nguyen LM, Burris H, et al. Phase I study of LY2606368, a checkpoint kinase 1 inhibitor, in patients with advanced cancer. J Clin Oncol. 2016;34(15):1764-71.

41. Hong DS, Moore K, Patel M, Grant SC, Burris HA, William WN Jr, et al. Evaluation of Prexasertib, a checkpoint kinase 1 inhibitor, in a phase Ib study of patients with squamous cell carcinoma. Clin Cancer Res. 2018;24(14):3263-72.

42. Gadhikar MA, Zhang J, Shen L, Rao X, Wang J, Zhao M, et al. CDKN2A/p16 deletion in head and neck cancer cells is associated with CDK2 activation, replication stress, and vulnerability to CHK1 inhibition. Cancer Res. 2018;78(3):781-97.

43. Karam SD, Reddy K, Blatchford PJ, Waxweiler T, DeLouize AM, Oweida A, et al. Final report of a phase I trial of Olaparib with Cetuximab and radiation for heavy smoker patients with locally advanced head and neck cancer. Clin Cancer Res. 2018;24(20):4949-59.

44. Weber AM, Ryan AJ. ATM and ATR as therapeutic targets in cancer. Pharmacol Ther. 2015;149:124-38.

45. Glorieux M, Dok R, Nuyts S. Novel DNA targeted therapies for head and neck cancers: clinical potential and biomarkers. Oncotarget. 2017;8(46):81662-78.

46. Leonard BC, Lee ED, Bhola NE, Li H, Sogaard KK, Bakkenist CJ, et al. ATR inhibition sensitizes $\mathrm{HPV}(-)$ and $\mathrm{HPV}(+)$ head and neck squamous cell carcinoma to cisplatin. Oral Oncol. 2019;95:35-42.

47. Krebs M, Lopez J, El-Khoueiry A, Bang Y, Postel-Vinay S, Abidah A, et al. Phase I clinical and transitional evaluation of AZD6738 in combination with durvalumab in patients with lung or head and neck carcinoma. Ann Oncol. 2018;28(suppl_8):viii133-viii48.

48. Friedman J, Morisada M, Sun L, Moore EC, Padget M, Hodge JW, et al. Inhibition of WEE1 kinase and cell cycle checkpoint activation sensitizes head and neck cancers to natural killer cell therapies. J Immunother Cancer. 2018;6(1):59.

49. Seibold ND, Schild SE, Bruchhage KL, Gebhard MP, Noack F, Rades D. Prognostic impact of VEGF and FLT-1 receptor expression in patients with locally advanced squamous cell carcinoma of the head and neck. Strahlentherapie und Onkologie: Organ der Deutschen Rontgengesellschaft [et al]. 2013;189(8):639-46.

50. Zang J, Li C, Zhao LN, Shi M, Zhou YC, Wang JH, et al. Prognostic value of vascular endothelial growth factor in patients with head and neck cancer: a meta-analysis. Head Neck. 2013;35(10):1507-14.

51. Machiels JP, Bossi P, Menis J, Lia M, Fortpied C, Liu Y, et al. Activity and safety of afatinib in a window preoperative EORTC study in patients with squamous cell carcinoma of the head and neck (SCCHN). Ann Oncol. 2018;29(4):985-91.

52. Lalami Y, Garcia C, Flamen P, Ameye L, Paesmans M, Awada A. Phase II trial evaluating the efficacy of sorafenib (BAY 43-9006) and correlating early fluorodeoxyglucose positron emission tomography-CT response to outcome in patients with recurrent and/or metastatic head and neck cancer. Head Neck. 2016;38(3):347-54.

53. Swiecicki PL, Zhao L, Belile E, Sacco AG, Chepeha DB, Dobrosotskaya I, et al. A phase II study evaluating axitinib in patients with unresectable, recurrent or metastatic head and neck cancer. Investig New Drugs. 2015;33(6):1248-56.

54. Gilbert J, Schell MJ, Zhao X, Murphy B, Tanvetyanon T, Leon ME, et al. A randomized phase II efficacy and correlative studies of cetuximab with or without sorafenib in recurrent and/or metastatic head and neck squamous cell carcinoma. Oral Oncol. 2015;51(4):376-82. 
55. Limaye S, Riley S, Zhao S, O'Neill A, Posner M, Adkins D, et al. A randomized phase II study of docetaxel with or without vandetanib in recurrent or metastatic squamous cell carcinoma of head and neck (SCCHN). Oral Oncol. 2013;49(8):835-41.

56. Elser C, Siu LL, Winquist E, Agulnik M, Pond GR, Chin SF, et al. Phase II trial of sorafenib in patients with recurrent or metastatic squamous cell carcinoma of the head and neck or nasopharyngeal carcinoma. J Clin Oncol Off J Am Soc Clin Oncol. 2007;25(24):3766-73.

57. Williamson SK, Moon J, Huang CH, Guaglianone PP, LeBlanc M, Wolf GT, et al. Phase II evaluation of sorafenib in advanced and metastatic squamous cell carcinoma of the head and neck: southwest oncology group study S0420. J Clin Oncol Off J Am Soc Clin Oncol. 2010;28(20):3330-5.

58. Machiels JP, Henry S, Zanetta S, Kaminsky MC, Michoux N, Rommel D, et al. Phase II study of sunitinib in recurrent or metastatic squamous cell carcinoma of the head and neck: GORTEC 2006-01. J Clin Oncol Off J Am Soc Clin Oncol. 2010;28(1):21-8.

59. Choong NW, Kozloff M, Taber D, Hu HS, Wade J, Ivy P, et al. Phase II study of sunitinib malate in head and neck squamous cell carcinoma. Investig New Drugs. 2010;28(5):677-83.

60. Fountzilas G, Fragkoulidi A, Kalogera-Fountzila A, Nikolaidou M, Bobos M, Calderaro J, et al. A phase II study of sunitinib in patients with recurrent and/or metastatic non-nasopharyngeal head and neck cancer. Cancer Chemother Pharmacol. 2010;65(4):649-60.

61. Fury MG, Zahalsky A, Wong R, Venkatraman E, Lis E, Hann L, et al. A phase II study of SU5416 in patients with advanced or recurrent head and neck cancers. Investig New Drugs. 2007;25(2):165-72.

62. Adkins D, Mehan P, Ley J, Siegel MJ, Siegel BA, Dehdashti F, et al. Pazopanib plus cetuximab in recurrent or metastatic head and neck squamous cell carcinoma: an open-label, phase $1 \mathrm{~b}$ and expansion study. Lancet Oncol. 2018;19(8):1082-93.

63. Blumenschein GR, Glisson BS, Lu C, Sabichi AL, Ginsberg LE, Bartos CI, et al. Final results of a phase II study of sorafenib in combination with carboplatin and paclitaxel in patients with metastatic or recurrent squamous cell cancer of the head and neck (SCCHN). J Clin Oncol. 2012;30(suppl; abstr 5592):2012.

64. Argiris A, Bauman JE, Ohr J, Gooding WE, Heron DE, Duvvuri U, et al. Phase II randomized trial of radiation therapy, cetuximab, and pemetrexed with or without bevacizumab in patients with locally advanced head and neck cancer. Ann Oncol. 2016;27(8):1594-600.

65. Argiris A, Karamouzis MV, Gooding WE, Branstetter BF, Zhong S, Raez LE, et al. Phase II trial of pemetrexed and bevacizumab in patients with recurrent or metastatic head and neck cancer. J Clin Oncol Off J Am Soc Clin Oncol. 2011;29(9):1140-5.

66. Argiris A, Li S, Savvides P, Ohr JP, Gilbert J, Levine MA, et al. Phase III randomized trial of chemotherapy with or without Bevacizumab in patients with recurrent or metastatic head and neck cancer. J Clin Oncol. 2019;37(34):3266-74.

67. Argiris A, Kotsakis AP, Hoang T, Worden FP, Savvides P, Gibson MK, et al. Cetuximab and bevacizumab: preclinical data and phase II trial in recurrent or metastatic squamous cell carcinoma of the head and neck. Annals of oncology: official journal of the European Society for Medical Oncology/ESMO. 2013;24(1):220-5.

68. Cohen EE, Davis DW, Karrison TG, Seiwert TY, Wong SJ, Nattam S, et al. Erlotinib and bevacizumab in patients with recurrent or metastatic squamous-cell carcinoma of the head and neck: a phase I/II study. Lancet Oncol. 2009;10(3):247-57.

69. Endhardt K, Khattri A, Keck M, Zuo Z, Rieke D, Ress A, et al. Harvey ras (HRAS) mutations in head and neck cancer $(\mathrm{HNC})$ and dependence on PI3K signaling and resistance to EGFR inhibition. J Clin Oncol. 2014;32(15):6034.

70. Li H, Wawrose JS, Gooding WE, Garraway LA, Lui VW, Peyser ND, et al. Genomic analysis of head and neck squamous cell carcinoma cell lines and human tumors: a rational approach to preclinical model selection. Molecular cancer research: MCR. 2014;12(4):571-82.

71. Cancers TTHRAS-M. Cancer Discov. 2019;9(12):1637-8. 
72. Ho A, Brana I, Haddad R, Bauman J, Bible K, Faugeras L, et al. Preliminary results from a phase 2 trial of tipifarnib in head and neck squamous cell carcinomas (HNSCCs) with HRAS mutations. In: AACR-NCI-EORTC presentation; 2019.

73. Ho A, Hanna G, Scholz C, Gualberto A, SH O. Preliminary activity of tipifarnib in tumors of the head and neck, salivary gland and urothelial tract with HRAS mutations. J Clin Oncol. 2020;38(suppl):6504.

74. Weber A, Langhanki L, Sommerer F, Markwarth A, Wittekind C, Tannapfel A. Mutations of the BRAF gene in squamous cell carcinoma of the head and neck. Oncogene. 2003;22(30):4757-9.

75. Subbiah V, Kreitman RJ, Wainberg ZA, Cho JY, Schellens JHM, Soria JC, et al. Dabrafenib and Trametinib treatment in patients with locally advanced or metastatic BRAF V600-mutant anaplastic thyroid cancer. J Clin Oncol. 2018;36(1):7-13.

76. Brooks AN, Kilgour E, Smith PD. Molecular pathways: fibroblast growth factor signaling: a new therapeutic opportunity in cancer. Clin Cancer Res. 2012;18(7):1855-62.

77. Collin MP, Lobell M, Hubsch W, Brohm D, Schirok H, Jautelat R, et al. Discovery of Rogaratinib (BAY 1163877): a pan-FGFR inhibitor. Chem Med Chem. 2018;13(5):437-45.

78. Helsten T, Elkin S, Arthur E, Tomson BN, Carter J, Kurzrock R. The FGFR landscape in cancer: analysis of 4,853 tumors by next-generation sequencing. Clin Cancer Res. 2016;22(1):259-67.

79. Goke F, Franzen A, Hinz TK, Marek LA, Yoon P, Sharma R, et al. FGFR1 expression levels predict BGJ398 sensitivity of FGFR1-dependent head and neck squamous cell Cancers. Clin Cancer Res. 2015;21(19):4356-64.

80. Joerger M, Soo R, Cho B, Navarro A, Mendivil C, Sayehli C, et al. Phase I study of the panfibroblast growth factor receptor (FGFR) inhibitor BAY 1163877 with expansion cohorts for subjects based on tumor FGFR mRNA expression levels. Ann Oncol. 2016;27(6):1-36.

81. McDermott SC, Rodriguez-Ramirez C, McDermott SP, Wicha MS, Nor JE. FGFR signaling regulates resistance of head and neck cancer stem cells to cisplatin. Oncotarget. 2018;9(38):25148-65.

82. Kupferman ME, Jiffar T, El-Naggar A, Yilmaz T, Zhou G, Xie T, et al. TrkB induces EMT and has a key role in invasion of head and neck squamous cell carcinoma. Oncogene. 2010;29(14):2047-59.

83. Lee J, Jiffar T, Kupferman ME. A novel role for BDNF-TrkB in the regulation of chemotherapy resistance in head and neck squamous cell carcinoma. PLoS One. 2012;7(1):e30246.

84. Drilon A, Laetsch TW, Kummar S, DuBois SG, Lassen UN, Demetri GD, et al. Efficacy of Larotrectinib in TRK fusion-positive Cancers in adults and children. N Engl J Med. 2018;378(8):731-9.

85. Doebele RC, Drilon A, Paz-Ares L, Siena S, Shaw AT, Farago AF, et al. Entrectinib in patients with advanced or metastatic NTRK fusion-positive solid tumours: integrated analysis of three phase 1-2 trials. Lancet Oncol. 2020;21(2):271-82.

86. Cocco E, Scaltriti M, Drilon A. NTRK fusion-positive cancers and TRK inhibitor therapy. Nat Rev Clin Oncol. 2018;15(12):731-47.

Open Access This chapter is licensed under the terms of the Creative Commons Attribution 4.0 International License (http://creativecommons.org/licenses/by/4.0/), which permits use, sharing, adaptation, distribution and reproduction in any medium or format, as long as you give appropriate credit to the original author(s) and the source, provide a link to the Creative Commons license and indicate if changes were made.

The images or other third party material in this chapter are included in the chapter's Creative Commons license, unless indicated otherwise in a credit line to the material. If material is not included in the chapter's Creative Commons license and your intended use is not permitted by statutory regulation or exceeds the permitted use, you will need to obtain permission directly from the copyright holder.

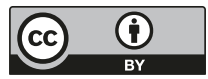

